\title{
Study the Effect of High Dialysate Potassium Solution in Comparison to Low Potassium Dialysate Solution in End Stage Renal Disease Patients
}

\author{
Mohammad Nourizadeh ${ }^{1}$, Masih Shakeri ${ }^{1}$, Seyed Seifolah Beladi Mousavi ${ }^{1}$, \\ Mohammad Hassan Adel', Mohammad Hossein Najafi'1, Zahra Rezaee1, \\ Mehdi Nourizadeh', Sara Nourizadeh ${ }^{2}$ \\ ${ }^{1}$ Atherosclerosis Research Centre, Ahvaz Jundishapur University of Medical Sciences, Ahvaz, Iran \\ ${ }^{2}$ Department of Cell \& Molecular Biology, Faculty of Biological Sciences, Kharazmi University, Tehran, Iran \\ Email: *mnoori_2000@yahoo.com
}

Received 18 December 2015; accepted 26 February 2016; published 29 February 2016

Copyright (C) 2016 by authors and Scientific Research Publishing Inc.

This work is licensed under the Creative Commons Attribution International License (CC BY). http://creativecommons.org/licenses/by/4.0/

(c) (i) Open Access

\begin{abstract}
Background: Nowadays cardiovascular diseases remain as the single most common cause of death in chronic dialysis patients; the aim of this study was to evaluate the effects of two different regimens of dialysis potassium removal in patients with a tendency to develop arrhythmias during haemodialysis (HD). Methods and Materials: There were 88 (36 men and 52 women) end stage renal disease (ESRD) patients recruited for the study. They received regular haemodialysis three times per week at the haemodialysis units of a university medical centre (Golestan hospital) during year 2011. We compared the arrhythmogenic effects of two dialysis techniques. Results: There was a tendency in the HD solution with constant $(3 \mathrm{mEq} / \mathrm{l}) \mathrm{K}$ for premature ventricular complex (PVC) appearance in to be reduced as compared with constant $(2 \mathrm{mEq} / \mathrm{l}) \mathrm{K}$ in the time of dialysis period, although this reduction was not statistically significant $(P=0.09)$. There was a significant reduction in SVC in the HD solution with constant $(3 \mathrm{mEq} / \mathrm{l}) \mathrm{K}$ as compared with constant $(2 \mathrm{mEq} / \mathrm{l})$ $K$. Discussion: In conclusion, the use of a model of intra-HD potassium that is more close to potassium serum concentration of ESRD patients can reduce the arrhythmogenic effect of HD in patients on regular HD treatment.
\end{abstract}

\section{Keywords}

Arrhythmia, Dialysis, End Stage Renal Disease

\footnotetext{
${ }^{*}$ Corresponding author.
}

How to cite this paper: Nourizadeh, M., Shakeri, M., Mousavi, S.S.B., Adel, M.H., Najafi, M.H., Rezaee, Z., Nourizadeh, M. and Nourizadeh, S. (2016) Study the Effect of High Dialysate Potassium Solution in Comparison to Low Potassium Dialysate Solution in End Stage Renal Disease Patients. Health, 8, 363-369. http://dx.doi.org/10.4236/health.2016.84038 


\section{Introduction}

Although these days a wide range of progressions take place in dialysis technology, cardiovascular diseases remain as the single most common cause of death in chronic dialysis patients [1]. One of the major causes of death in end-stage renal disease (ESRD) patients under maintenance haemodialysis (HD) is ventricular arrhythmias [2].

Although uremic patients usually already have a decreased potassium pool [3] [4], in order to counterbalance the interdialysis potassium load and avoid life-threatening hyperkalaemia, potassium is removed by HD. Unlike HD sodium removal, which can even be exclusively convective [5] [6], HD potassium removal is almost exclusively diffusive. It is therefore necessary to create a gradient between plasma and dialysate potassium concentrations, which means greatly reducing plasma potassium concentrations during HD. However, very different amounts of potassium removal can be obtained with quite small differences in the dialysate plasma gradient since the potassium removal is mainly due to a decrease in the intracellular potassium pool.

However, relatively few studies have examined patient and HD-specific factors that might be associated with a higher risk of developing cardiac arrhythmias. The arrhythmogenic effect of HD was considered not only because of its still discussed clinical importance, but also because it is a "marker" of the electrophysiological status of the cells of uremic patients, which are greatly modified during standard HD treatment three times a week for many years [7].

Hence, we have undertaken this study of arrhythmias in order to evaluate the role of one of the major factors in the genesis of HD arrhythmias, potassium $(\mathrm{K})$ changes during dialysis.

We have evaluated the effects of two different regimens of dialysis potassium removal in patients with a tendency to develop arrhythmias during HD. Our chief interest was to identify the regimen of the least susceptibility to cardiac rhythm disorders during the dialysis cycle.

\section{Methods}

\section{End-stage renal failure patients}

There were 88 (36 men and 52 women) ESRD patients recruited for the study. They received regular haemodialysis three times per week at the haemodialysis units of a university medical centre (Golestan hospital) during year 2011. All the patients have received a written informed consent approved by Ahwaz Jondishapour research ethic board, and they all agreed to participant the research. Clinical indication for haemodialysis in the present study population is divided into two categories: 1 ) absolute indication with creatinine clearance rate $(\mathrm{Ccr})<5$ $\mathrm{ml} / \mathrm{min}$ or serum creatinine $(\mathrm{Cr})>8.0 \mathrm{mg} / \mathrm{dl}$; 2 ) relative indication with $\mathrm{Ccr}<15 \mathrm{ml} / \mathrm{min}$ or serum $\mathrm{Cr}>6 \mathrm{mg} / \mathrm{dl}$ and with accompanying life threatening complications as congestive heart failure, lung edema, haemorrhage diathesis, consciousness change, cachexia or uncontrollable hyperkalaemia with drugs. Uremic patients on stable HD treatment were recruited. After they had given their oral consent, the patients fulfilling the entry criteria were selected for the experimental phase.

Inclusion criteria

Patients aged more than 18 years, who had been on chronic thrice-weekly HD for at least six months, and who were in stable clinical condition were admitted to the study. The continuous 24 hours electrocardiographic (ECG) recording made on the HD day was performed for each patient.

Exclusion criteria

Patients on antiarrhythmic treatment or receiving pace-maker cardiac stimulation, those whose dosage of digitalis was unstable, and those requiring dialysate $\mathrm{K}$ concentration of more than $3 \mathrm{mEq} / \mathrm{litter}$ were excluded from the study.

Haemodialysis

The patients had to undergo HD at the same time of day for both treatments in order to avoid any interference with the circadian rhythms of arrhythmia. In patient and throughout the three weeks of the study, only the concentration of dialysate $\mathrm{K}$ could change, and then only in accordance with the study protocol.

Twenty-four hour EGG recording on the HD day, continuous 24-hour EGG recording was started at the time of HD. The 24-hour EGG signal was recorded and the tapes were centrally analysed for ventricular arrhythmias.

The readers were blinded as to treatment.

Treatment definitions

All uremic patients that had inclusion criteria randomly divided into two groups. Group A (consist of 44 patients) Standard HD with a dialysate K concentration of $3 \mathrm{mEq} /$ litter. Group B (consist of 44 patients) Experi- 
mental HD with dialysate $\mathrm{K}_{2} \mathrm{mEq} /$ lit concentration were performed for them.

The calculated sample size of 88 patients was based on: a significance level (an error) of 0.05 ; a $\beta$ error of 0.2 ; a power [1- $\beta$ ] of 0.8 ; after gathering data they were analyse by using SPSS soft ware version 16 and ANOVA and student $\mathrm{T}$ test was used for analysing data.

A Holter recording selection some of the 24-hour Holter recordings were considered totally unsuitable for analysis because of the bad quality of the ECG signal (presence of superimposed noise, incorrect positioning of the electrodes) and the consequent inability to distinguish normal beats from pathological PVCs. The bad signal quality was sometimes present during only a part of some of the recordings, leading to temporary gaps in which the PVCs could not be detected.

\section{Results}

88 ESRD patients (36 male) were recruited in the study. The mean age of patients was $58.6 \pm 8.3$ (Table 1 ).

As its shown in Table 2 the mean age of patients and the electrolyte levels of two groups of ESRD patients [with dialysate potassium solution of $2 \mathrm{mEq} / \mathrm{lit}\left(\mathrm{k}_{2}\right)$ and Dialysate potassium of $3 \mathrm{mEq} / \mathrm{lit}\left(\mathrm{k}_{3}\right)$ ] were comparable and had not significant change $(\mathrm{P}>0.05)$.

The serum electrolyte levels of NA, K, BUN, CR, CA, P, PH after dialysis were decreased significantly $(\mathrm{P}<$ 0.05) (Table 3).

As shown in Table 4 it was a trend for PVC, AF to increase with potassium solution of $2 \mathrm{mEq} /$ lit (numbers of PVC, AF in patients with potassium solution of $2 \mathrm{mEq} / \mathrm{lit}$ was $37.7 \pm 6.1,13.28 \pm 0.5$ and in patients with potassium solution of $3 \mathrm{mEq} /$ lit these were $12.4 \pm 1.6$, $9.2 \pm 0.4$ ). Significant change was seen with $\mathrm{K}_{2}$ in the number of SVC.

Table 5 shows an increase in the difference of potassium before and after dialysis lead to significant change in the number of PVC and SVC.

Table 1. Age and sex distribution of end stage renal disease patients.

\begin{tabular}{ccc}
\hline Gender & Number/percent & Age \\
\hline Male & $36(40.9 \%)$ & $57.5 \pm 8$ \\
Female & $52(59.1 \%)$ & $60 \pm 8.2$ \\
Total patients & 88 & $58.6 \pm 8.3$ \\
\hline
\end{tabular}

Table 2. Electrolyte and age distribution in different dialysis potassium solution.

\begin{tabular}{cccc}
\hline Hg solution (mEq/l) & Mean & STD. Deviation \\
\hline NA & $\mathrm{K}_{2}$ & 58.2 & 7.1 \\
& $\mathrm{~K}_{3}$ & 59.5 & 9.2 \\
K & $\mathrm{K}_{2}$ & 135.2 & 4.02738 \\
& $\mathrm{~K}_{3}$ & 134 & 2.30503 \\
BUN & $\mathrm{K}_{2}$ & 5.3786 & 0.56046 \\
& $\mathrm{~K}_{3}$ & 5.1400 & 0.53449 \\
CR & $\mathrm{K}_{2}$ & 72.6429 & 16.23674 \\
& $\mathrm{~K}_{3}$ & 61.5000 & 25.28469 \\
P & $\mathrm{K}_{2}$ & 9.1429 & 2.88009 \\
& $\mathrm{~K}_{3}$ & 7.2450 & 2.38867 \\
PH & $\mathrm{K}_{2}$ & 6.1357 & 0.95241 \\
& $\mathrm{~K}_{3}$ & 5.2250 & 1.72623 \\
$\mathrm{~K}_{2}$ & $\mathrm{~K}_{3}$ & 7.2900 & 0.03397 \\
\hline
\end{tabular}


Table 3. Electrolytes changes before and after hem dialysis in ESRD patients.

\begin{tabular}{cccc}
\hline Electrolyte & Mean before dialysis & Mean after dialysis & P value \\
\hline NA mEq/l & 134 & 136 & 0.02 \\
$\mathbf{K ~ m E q / l ~}$ & 5.2 & 3.5 & $<0.01$ \\
$\mathbf{B U N ~ m g / d L}$ & 66.0882 & 22.0882 & $<0.01$ \\
$\mathbf{C R} \mathrm{mg} / \mathrm{dL}$ & 8.0265 & 3.2206 & $<0.01$ \\
$\mathbf{C A ~ M g} / \mathrm{dL}$ & 9.2 & 8.70 & $<0.01$ \\
$\mathbf{P} \mathrm{mEq} / \mathrm{l}$ & 5.6 & 3.8 & $<0.01$ \\
$\mathbf{P H ~ N m o l} / \mathrm{l}$ & 6.07 & 5.1 & $<0.01$ \\
\hline
\end{tabular}

Table 4. Numbers and standard deviation and confidence interval of PVC and AF and SVC in two different potassium solutions.

\begin{tabular}{|c|c|c|c|c|c|c|}
\hline $\begin{array}{c}\text { Type of } \\
\text { arrhythmia }\end{array}$ & $\begin{array}{l}\text { Type of HD } \\
\text { SOLOTION }\end{array}$ & Numbers/percent & Standard deviation & \multicolumn{2}{|c|}{ CI (95\%) } & $P$ value \\
\hline \multirow{2}{*}{ PVC } & $\mathrm{K} 2$ & 37.7 & 6.1 & $(-4$ & 54) & \multirow{2}{*}{0.09} \\
\hline & K3 & 12.4 & 1.6 & $(-11$ & 61) & \\
\hline \multirow{2}{*}{ SVC } & K2 & 297 & 5.5 & $(13$ & 50) & \multirow{2}{*}{0.03} \\
\hline & K3 & 51 & 9.6 & $(7$ & 57) & \\
\hline \multirow{2}{*}{$\mathbf{A F}$} & K2 & $13 / 28 \%$ & 0.5 & $(-0.5$ & $0.9)$ & \multirow{2}{*}{0.07} \\
\hline & K3 & $9 / 20 \%$ & 0.4 & $(-0.5$ & $0.11)$ & \\
\hline
\end{tabular}

Table 5. Mean potassium differences in plasma of ESRD patients in different dialysate potassium solution and number of PVC and SVC in them.

\begin{tabular}{ccccc}
\hline Patients & Mean potassium differences $(\mathbf{m E q} / \mathbf{l})$ & PVC & SVC & P value \\
\hline $\mathrm{K}_{2}$ & 2 & 37 & 297 & $<0.05$ \\
$\mathrm{~K}_{3}$ & 1.5 & 12.4 & 51 & $<0.05$ \\
\hline
\end{tabular}

\section{Discussion}

In HD with dialysate potassium solution of $3 \mathrm{mEq} / \mathrm{lit}$, a lower appearance of PVC as compared to dialysate potassium solution of $2 \mathrm{mEq} / \mathrm{lit}$ was apparent, even though the difference did not turn out to be statistically significant $(\mathrm{P}=0.09)$, but SVC appeared more in group with dialysate potassium solution of $2 \mathrm{mEq} /$ lit no significant difference was found between the two treatments in either isolated PVC, or pairs or runs. Again, there was no statistical difference between the two treatments in regarding to electrolytes.

Studies on dialytic potassium removal [8] [9] show that the higher the plasma dialysate potassium gradient, the greater the potassium removal from intracellular fluid. The uraemia related inhibition of the Na-K pump produces a potassium shift from intra-to extracellular fluid and consequently induces hyperkalaemia; thus, the more advanced the cellular sickness, the bigger the cellular depauperation of Potassium during analysis. Consequently, there is a vicious circle: although it improves the function of the Na-K pump, dialysis treatment maintains and even increases cellular distress by reducing the intracellular potassium pool. Thus, in our opinion, the new approach explored in this study seems to be particularly suitable for patients prone to life-threatening hyperkalaemia [10]-[12].

It is known from physiology studies that the wholeness of the cellular potassium pool is necessary to many cellular functions: volume and PH regulation [13].

Given selective cell permeability to potassium (K), the resting electric membrane potential (REMP) of most cells is related to the diffusive passive fluxes of $\mathrm{K}$ ions [14]. The level of REMP affects cell excitability: the greater the difference between REMP and the threshold level of the electric potential, the longer the depolarization time [15] [16].

In chronic haemodialysis (HD) patients, intradialytic $\mathrm{K}$ is removed by diffusion throughout the HD membrane, according to the concentration gradient between plasma and dialysate $\mathrm{K}$ levels. With constant dialysate $\mathrm{K}$ levels 
of $2 \mathrm{mEq} / \mathrm{lit}$, this gradient decreases rapidly during the first hour of HD and slowly in the following hours. The diffusive fluxes of $\mathrm{K}$ through the HD membrane produce diffusive passive fluxes through the membrane cells, with greater negativization of membrane of cells and, consequently, less cell membrane excitability. This phenomenon is more evident during the first hour of $\mathrm{HD}$, since the plasma-dialysate $\mathrm{K}$ gradient is higher.

The changes in K fluxes induced by HD may therefore influence cardiac cell electrophysiology, and it may lead to cardiac arrhythmias.

In HD with constant and low potassium (range $2 \mathrm{mEq} / \mathrm{l}$ ) a large amount of potassium is abruptly removed from the extracellular space [17].

The depletion of the potassium reserves within the cells may have important repercussions on cardiac electrophysiology.

Another mechanism by which potassium change lead to cardiac arrhythmia is that Potassium fluxes during HD have been associated with an increase in QT interval [18] [19], an increase in the dispersion of QT and in the inhomogeneous repolarisation revealed by the analysis of the spatial aspects of T-wave complexity [20]. The resulting repolarisation heterogeneity allows for the onset of distinctive re-entrant arrhythmias, and hypokalaemia may act as a triggering factor in the genesis of premature ventricular depolarisations. The incidence of related ECG abnormalities during HD ranges from $18 \%$ to $76 \%$, depending on the definition of the abnormal ventricular electrical activity [21].

An Italian study by Redaelli et al. [22] has demonstrated a 36\% reduction in premature ventricular complexes using a profiling of potassium dialysate concentration in arrhythmic HD patients. Morrison et al. [23] demonstrated decreased ventricular ectopic activity in four out of six patients whose dialysate potassium concentration had changed from 2 to $3.5 \mathrm{mEq} / \mathrm{lit}$. In our study, the serum potassium trends are significantly different with the use of constant $\mathrm{K}$ concentration $(3 \mathrm{mEq} / \mathrm{l})$ in comparison with $(2 \mathrm{mEq} / \mathrm{l}) \mathrm{K}$ dialysate concentration and in our study the number of PVC increased more than 3 times in dialysate solution with potassium $2 \mathrm{mEq} / \mathrm{l}$ that was very close to the result of Redaelli et al. on the other hand SVC numbers raised more than 5 times independently.

Rombol`a et al. [24] found like us a greater fall in intra-erythrocyte potassium concentration in patients with an arrhythmic tendency, as compared to those without such a tendency [25] but he didn't exactly mention witch kind of arrhythmia are more prone to the potassium changes.

In our opinion analysis of data support Rombol'a idea that some stressors such as fluid overload, increase in blood pressure and the changes in $\mathrm{pH}$ and bicarbonates, may act as trigger of ventricular arrhythmias [26]. Obviously this may be particularly true for patients with cardiomyopathy, left-ventricular hypertrophy, coronary artery disease and cardiac heart failure, which provide the perfect backdrop for arrhythmias to occur [27].

Naturally, these demonstrate a higher incidence of sudden death in a group of patients treated by HD with constant $2 \mathrm{mEq} / \mathrm{l}$ potassium dialysate in comparison with another group treated with constant $3 \mathrm{mEq} / \mathrm{l}$ potassium solutions.

\section{Conclusion}

In conclusion, the use of a model of intra-HD potassium that is more close to potassium serum concentration of ESRD patients can decrease the arrhythmogenic effect of HD in patients on regular HD treatment. This result was obtained without adversely affecting pre-dialysis plasma potassium levels in comparison with the standard HD procedure. The results of this study not only showed that the amount of cardiac arrhythmia raised more in potassium concentration of $2 \mathrm{mEq} /$ lit but also demonstrated that supra ventricular arrhythmias are more influenced by those changes. The results of this study clearly illustrate that the use of a model of HD potassium removal which is more close to blood concentration of potassium is capable of reducing the arrhythmogenic effect of standard HD in chronic uremic patients prone to this complication. This decrease was statistically and clinically significant for both PVC and SVC.

\section{References}

[1] Eknoyan, G. and Levin, N.W. (2002) K/DQI Clinical Practice Guide Lines for Chronic Kidney Disease: Evaluation, Classification, and Stratification. American Journal of Kidney Diseases, 39, 51.

[2] Aghighi, M., Rouchi, A.H., Zamyodi, M., Machdavi-Mazdeh, M., Norouzish, S., Rajolani, H., et al. (2008) Dialysis in Iran. Iranian Journal of Kidney Diseases, 2, 11-15. 
[3] Nafar, M., Mousavi, S.M., Mahdavi-Mazbeh, M., Pour-Reza-Gholi, F., Firoozan, A. and Einollahi, B. (2008) Burden of Chronic Kidney Disease in Iran: A Screening Program Is of Essential Need. Iranian Journal of Kidney Diseases, 2, 115-169.

[4] Bruno, R., Francesco, L., Donatella, L. and Simeon, A. (1996) Effect of a New Model of Haemodialysis Potassium Removal on the Control of Ventricular Arrhythmias. Kidney International, 50, 609-617. http://dx.doi.org/10.1038/ki.1996.356

[5] Wen, T.L., Chung-Kwe, W., Yang, I.F. and Yang, T.F. (2007) Relationship between Electrolytes and Heart Rate Variability Parameters in End-Stage Renal Failure Patients before and after Haemodialysis. Anadolu Kardiyoloji Dergisi, 7, $142-144$

[6] Santoro, A., Mancini, E., London, G., Mercadal, L., Fessy, H., Perrone, B., Cagnoli, L., Grandi, E., Severi, S. and Cavalcanti, S. (2008) Patients with Complex Arrhythmias during and after Haemodialysis Suffer from Different Regimens of Potassium Removal. Nephrology, Dialysis, Transplantion, 23, 1415-1421. http://dx.doi.org/10.1093/ndt/gfm730

[7] Table, H. (2003) Death Rates by Cause of Death: Dialysis Patients Unadjusted. In: U.S. Renal Data System, Ed., USRDS 2003 Annual Data Report: Atlas of End-Stage Renal Disease in the United States, Bethesda, 484-492.

[8] Herzog, C.A., Muster, H.A., Li, S. and Collins, A.J. (2004) Impact of Congestive Heart Failure, Chronic Kidney Disease, and Anemia on Survival in the Medicare Population. Journal of Cardiac Failure, 10, 467-472. http://dx.doi.org/10.1016/j.cardfail.2004.03.003

[9] London, G.M. (2003) Cardiovascular Disease in Chronic Renal Failure: Pathophysiologic Aspects; the Clinical Epidemiology of Cardiovascular Diseases in Chronic Kidney Disease. Seminars in Dialysis, 16, 85-94. http://dx.doi.org/10.1046/j.1525-139X.2003.16023.x

[10] Bleyer, A.J., Hartman, J., Brannon, P.C., et al. (2006) Characteristics of Sudden Death in Haemodialysis Patients. Kidney International, 69, 2268-2273. http://dx.doi.org/10.1038/sj.ki.5000446

[11] Santoro, A., Mancini, E., Fontanazzi, F. and Paolini, F. (2002) Potassium Profiling in Acetate Free Biofiltration. In: Ronco, C. and La Greca, G., Eds., Hemodialysis Technology, Contributions to Nephrology, Vol. 137, Karger, Basel, 260-267. http://dx.doi.org/10.1159/000060222

[12] Sherman, R.A., Hwang, E.R., Bernholc, A.S. and Eisinger, R.P. (1986) Variability in Potassium Removal by Hemodialysis. American Journal of Nephrology, 6, 284-288. http://dx.doi.org/10.1159/000167176

[13] Cupisti, A., Galetta, F., Caprioli, R., Morelli, E., Tintori, G.C., Franzoni, F., Lippi, A., Meola, M., Rindi, P. and Barsotti, G. (1999) Potassium Removal Increases the QTc Interval Dispersion during Hemodialysis. Nephron, 82, 122-126. http://dx.doi.org/10.1159/000045387

[14] Weinor, M. and Epstein, F.F. (1979) Signs and Symptoms of Electrolyte Disorders. Yale Journal of Biology and Medicine, 43, 76-109.

[15] Genovesi, S., Rivera, R., Fabbrini, P., Dossi, C., Bonforte, G., Mircoli, L., Ferrari, A.U., Stella, A. and StrambaBadiale, M. (2003) Dynamic QT, Interval Analysis in Uraemic Patients Receiving Chronic Haemodialysis. Journal of Hypertension, 21, 1921-1926. http://dx.doi.org/10.1097/00004872-200310000-00020

[16] Hodgkin, A.L. and Huxley, A.F. (1952) A Quantitative Description of Membrane Current and Its Application to Conduction and Excitation in Nerve. The Journal of Physiology, 117, 500-544. http://dx.doi.org/10.1113/jphysiol.1952.sp004764

[17] Hodgkin, A.L. and Horowlcz, P. (1959) The Influence of Potassium and Chloride Ions on the Membrane Potential of Single Muscle Fibres. The Journal of Physiology, 148, 127-160. http://dx.doi.org/10.1113/jphysiol.1959.sp006278

[18] Adrian, R.H. (1956) The Effect of Internal-External Potassium Concentration on the Membrane Potential of Frog Muscle. The Journal of Physiology, 133, 631-658. http://dx.doi.org/10.1113/jphysiol.1956.sp005615

[19] Katz, A.M. (1993) Mechanisms of Disease. Cardiac Ion Channels. The New England Journal of Medicine, 328, 12441251. http://dx.doi.org/10.1056/NEJM199304293281707

[20] Kovcs, R.J., Bailey, J.C. and Zipe, D.P. (1988) Mechanism of Cardiac Arrhythmias. In: Parmley, W.W. and Chatterjee, K., Eds., Cardiology, Physiology, Pharmacology, Diagnosis, Lippincott Co., Philadelphia, 23.

[21] Waldo, A.L. and Vit, A.L. (1993) Mechanisms of Cardiac Arrhythmias. Lancet, 341, 1189-1193. http://dx.doi.org/10.1016/0140-6736(93)91012-B

[22] Redaelli, B., Locatelli, F., Limido, D., Andrulli, S., Signorini, M.G., Sforzini, S., Bonoldi, L., Vincenti, A., Cerutti, S. and Orlandini, G. (1996) Effect of a New Model of Hemodialysis Potassium Removal on the Control of Ventricular Arrhythmias. Kidney International, 50, 609-617. http://dx.doi.org/10.1038/ki.1996.356

[23] Morrison, G., Michelson, B.L., Brown, S. and Morganroth, J. (1980) Mechanism and Prevention of Cardiac Arrhythmias in Chronic Hemodialysis Patients. Kidney International, 17, 811-819. http://dx.doi.org/10.1038/ki.1980.93 
[24] Rombola, G., Colussi, G., De Ferrari, M.E., Frontini, A. and Minetti, L. (1992) Cardiac Arrhythmias and Electrolyte Changes during Haemodialysis. Nephrology Dialysis Transplantation, 7, 318-322.

[25] Gruppo Emodialisi e Patologie Cardiovascolari (1988) Multicentre, Cross-Sectional Study of Ventricular Arrhythmias in Chronically Hemodialysed Patients. Lancet, 2, 305-309.

[26] Weber, H., Schwarzer, C., Stummvoll, H.K., Joskowlcs, G., Wolf, A., Steinbach, K. and Kaindl, F. (1984) Chronic Hemodialysis: High Risk Patients for Arrhythmias? Nephron, 37, 180-185. http://dx.doi.org/10.1159/000183240

[27] Wizemann, V., Kramer, W., Funke, T. and Shutfede, U. (1985) Dialysis Induced Cardiac Arrhythmias: Fact or Fiction? Nephron, 39, 356-380. http://dx.doi.org/10.1159/000183405 